\title{
Analysis of engineering characteristics and foundation treatment methods of soft soil in Guyana Georgetown regine
}

\author{
YUAN Fanglong1,2,3,4,a, CHEN Yuntao 1,2,3,4,5,b, ZHU Yaoting 1,2,3,4, , \\ LI Dongjun ${ }^{1,2,3,4, d}$
}

${ }^{1}$ Tiajin Port Engineering Institute Ltd. of CCCC Tianjin, China

${ }^{2}$ CCCC First Harbor Engineering Company Ltd.Tianjin, China

${ }^{3}$ Key Laboratory of port geotechnical engineering, ministry of communications, PRC Tianjin, China

${ }^{4}$ Key Laboratory of port geotechnical engineering of Tianjin Tianjin, China

${ }^{5}$ Hebei University of Technology, Tianjin, China

a13821611543@163.com, bchenyuntao@163.com, ${ }^{\mathrm{C}} 15900369657 @ 163 . c o m,{ }^{\mathrm{d}} 272746353 @ q q . c o m$

Keywords: Soft soil; physical and mechanical properties; engineering geological problems; soft foundation treatment methods; sand pile composite drainage plate

\begin{abstract}
The clarification of the distributing disciplinarian and engineering properties of soft soil in Guyana Georgetown regions has important guiding significance for the design and construction of local projects. Based on Capital Airport Expansion Project, the physical and mechanical properties of the local soft soil are summarized and analyzed, Meanwhile, the applicability of the soft foundation treatment methods commonly used in China are discussed in conjunction with the major engineering geological problems, Finally, the effectiveness of the sand pile composite drainage plate method for the soft foundation treatment is analyzed. The research shows that: The distribute of soil layer along the depth are humus soil layer, muck layer, clay layer and medium fine sand layer; The humus soil layer and muck layer has the characteristics of high moisture content, high compressibility, low strength, high sensitivity and other unfavorable geology characteristics; After consolidation, the increase of shear strength of humus soil is not obvious, and the strength is still very low; The effectiveness of sand pile composite drainage plate for soft foundation reinforcement is verified, and the suggestions of remove the surface humus, appropriately prolong the preloading time, reduce the disturbance to the soil layer and some other rationalization proposal are put forward.
\end{abstract}

\section{Introduction}

With the rapid development of China's economy and the implementation of "the Belt and Road" international cooperation strategy, more and more enterprises have participated in the infrastructure construction of countries around the world. Ports, airports, railways, highways and other projects have started construction, There are great differences in the distribution laws and engineering characteristics of soil layers in various countries, and there are less information available for reference, As a result, many new engineering and technical problems are delayed due to lack of timely solution, Severely lead to major engineering accidents.

Soft soils have received great attention from domestic scholars due to poor engineering characteristics, such as low strength, high compressibility, and low bearing capacity [1-5]. At present, domestic soft foundation treatment technologies have achieved certain achievements [6-9], but research on the characteristics of foreign soft soils is still at an exploratory stage. ZHENG Xiao-jing et al. [10] summarized the experimental data of a large number of Dhaka soft clays, and the major engineering geological problems and foundation treatment methods were analyzed; WANG Jun-qiao [11] studied the mineral composition and physico-mechanical properties of volcanic ash-deposited soft soil in Bandung Indonesia by using X-ray diffraction analysis and geotechnical tests, but did not provide reasonable treatment suggestions for local soft foundations; HUANG Chen[12] studied and 
summarized the characteristics of soft soil foundation engineering in the Ganges Delta area, but did not propose specific soft foundation treatment measures.

Georgetown is the capital of Guyana, located in the northeastern of South America and is a coastal plain area, There are large unexplored tropical rainforest in the region, Study and summarize the distribution laws and the engineering characteristics of soft soil, provide reasonable suggestions for the soft foundation treatment, which has important guiding significance and practicality for the design and construction of local engineering. Based on the capital airport expansion project, this paper summarizes and analyzes the engineering characteristics of the soft soil foundation and the existing engineering geology problems in the construction, Finally, the effectiveness of the sand pile composite drainage plate soft ground treatment method adopted in the Capital Airport expansion project was analyzed.

\section{Engineering geological conditions}

\section{Regional geological conditions}

Guyana is dominated by plateau landforms. The western and southern parts of the country are relatively high in terrain and gently dip to the northeast, The Mesozoic and Cenozoic Paleogene-Neoprene alluvial formations are covered by the central and western regions. Georgetown is located in the northeast of Guyana and belongs to the coastal plain area, This area is covered by Quaternary sediments formed by Demerara river and its tributaries. The sediments are mainly composed of the Neogene Demerara clay and the early Coropina soil layers. The thickness gradually increases from west to east, and the newly deposited Layers of Demerara clay and modern sedimentary clays form part of the coast.

\section{Weather condition}

The Indian word for Guyana means "a land of many waters". It is a tropical climate with hot, humid and rainy conditions, and the monthly temperature, humidity, and precipitation do not change much. The average temperature in Georgetown is $25.4^{\circ} \mathrm{C}$ to $27.1^{\circ} \mathrm{C}$, the average humidity is $69 \%$ to $77 \%$, and the average precipitation is $120.5 \mathrm{~mm} 354.0 \mathrm{~mm}$. This area is under the control of the northeast trade wind, and the average monthly wind speed is 2 to 3 .

\section{Engineering characteristics of soft soil}

\section{Distribution of soil layer}

The quaternary alluvial deposits in Georgetown are thick, According to the age, burial conditions, distribution laws and other engineering geological characteristics of the soil layer, It is revealed that the topography of the soil distribution in the area is black humus soil layer $\mathrm{I}_{3}$, gray-black to gray muck layer II, gray to gray-white clay layer III, and gray-white medium-fine sand layer IV $_{1}$ (see Fig.1), in which the soft soil layer is $\mathrm{I}_{3}$ humus soil layer and II muck layer, exposing the thickness of the humus soil layer is $1.80 \mathrm{~m}$ to $5.30 \mathrm{~m}$, and the thickness of the muck layer is $0.90 \mathrm{~m}$ to $12.80 \mathrm{~m}$.

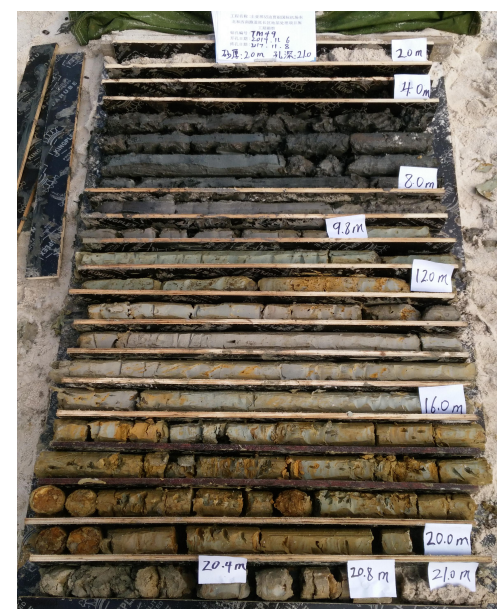

Fig.1 Distribution of soil layers in Guyana Georgetown region 


\section{Analysis of physical mechanical parameters and characteristics of soft soil}

Statistics of physical mechanical parameters and characteristics of soft soil

By screening soft soil samples taken from the investigation area of the Capital Airport expansion project in Guyana, the laboratory test results of 376 humus soil samples, 646 muck samples and 476 on-site cross-plate shear tests are finally taken for statistics after removing the abnormal values, The statistical results of the major physical and mechanical properties are shown in Table 1 and Table 2.

Table 1 Physical index statistics of soft soil in Georgetown region

\begin{tabular}{|c|c|c|c|c|c|c|c|c|c|c|}
\hline No. & \multicolumn{2}{|c|}{ Statistical item } & $\begin{array}{l}\text { Natural moisture content } \\
\omega[\%]\end{array}$ & $\begin{array}{c}\text { Gravity density } \\
\gamma\left[\mathrm{kN} / \mathrm{m}^{3}\right]\end{array}$ & $\begin{array}{l}\text { Void ratio } \\
e\end{array}$ & $\begin{array}{l}\text { Specific gravity } \\
\text { Gs }\end{array}$ & $\begin{array}{l}\text { Liquid limit } \\
\omega_{\mathrm{L}}[\%]\end{array}$ & $\begin{array}{l}\text { Plastic limit } \\
\omega_{\mathrm{p}}[\%]\end{array}$ & $\begin{array}{l}\text { Plastic index } \\
\quad I_{\mathrm{p}}\end{array}$ & $\begin{array}{c}\text { Liquidity index } \\
I_{\mathrm{L}}\end{array}$ \\
\hline \multirow{3}{*}{$\begin{array}{l}\mathrm{I}_{3} \text { humus } \\
\text { soil layer }\end{array}$} & \multicolumn{2}{|c|}{ Max. } & 202.0 & 14.0 & 4.039 & 2.54 & 134.0 & 80.0 & 54.0 & 1.54 \\
\hline & \multicolumn{2}{|c|}{ Min. } & 84.5 & 12.5 & 2.523 & 2.45 & 84.2 & 54.9 & 28.6 & 1.35 \\
\hline & \multicolumn{2}{|c|}{ Mean } & 149.5 & 13.1 & 3.361 & 2.47 & 104.3 & 66.5 & 41.7 & 1.44 \\
\hline \multirow{3}{*}{$\begin{array}{l}\text { II muck } \\
\text { layer }\end{array}$} & \multicolumn{2}{|c|}{ Max. } & 86.7 & 16.8 & 2.153 & 2.552 & 75.6 & 54.8 & 34.1 & 1.60 \\
\hline & \multicolumn{2}{|c|}{ Min. } & 50.3 & 14.1 & 1.228 & 2.341 & 53.8 & 31.1 & 17.9 & 0.78 \\
\hline & \multicolumn{2}{|c|}{ Mean } & 73.9 & 15.3 & 1.798 & 2.454 & 65.7 & 37.4 & 28.3 & 1.28 \\
\hline \multirow[b]{2}{*}{ No. } & \multirow[b]{2}{*}{$\begin{array}{l}\text { statistica } \\
1 \text { item }\end{array}$} & \multicolumn{2}{|c|}{ consolidated quick direct shear test } & \multicolumn{2}{|c|}{ direct shear test } & \multicolumn{2}{|c|}{ Triaxial test [UU] } & \multicolumn{3}{|c|}{ Vane-shear test } \\
\hline & & $\begin{array}{c}\text { Cohesion } \\
c[\mathrm{kPa}]\end{array}$ & $\begin{array}{c}\text { Internal friction } \\
\text { angle } \varphi\left[^{\circ}\right]\end{array}$ & $\begin{array}{c}\text { Cohesion } \\
c[\mathrm{kPa}]\end{array}$ & $\begin{array}{c}\text { Internal } \\
\text { friction angle } \\
\varphi\left[^{\circ}\right]\end{array}$ & $\begin{array}{l}\text { Cohesion } \\
c_{u}[\mathrm{kPa}]\end{array}$ & $\begin{array}{l}\text { Internal friction } \\
\text { angle } \varphi_{\mathrm{u}}\left[^{\circ}\right]\end{array}$ & $\begin{array}{l}\text { Undisturbed soil } \\
\quad \mathrm{C}_{u}[\mathrm{kPa}]\end{array}$ & $\begin{array}{l}\text { Remoulded soil } \\
\mathrm{C}_{\mathrm{u}}[\mathrm{kPa}]\end{array}$ & $\begin{array}{l}\text { Sensitivity } \\
\mathrm{S}_{\mathrm{t}}[\mathrm{kPa}]\end{array}$ \\
\hline \multirow{3}{*}{$\begin{array}{c}\mathrm{I}_{3} \\
\text { humus } \\
\text { soil } \\
\text { layer }\end{array}$} & Max. & 14.5 & 6.0 & 8.7 & 1.2 & 13.0 & 2.8 & 14.2 & 4.9 & 8.5 \\
\hline & Min. & 10.9 & 3.4 & 5.4 & 0.8 & 6.4 & 1.0 & 7.4 & 1.4 & 1.6 \\
\hline & Mean & 12.7 & 4.8 & 6.8 & 1.1 & 9.8 & 1.6 & 9.6 & 2.7 & 6.4 \\
\hline \multirow{3}{*}{$\begin{array}{l}\text { II muck } \\
\text { layer }\end{array}$} & Max. & 20.1 & 12.4 & 12.0 & 5.8 & 21.4 & 2.1 & 28.9 & 4.9 & 9.5 \\
\hline & Min. & 15.3 & 4.0 & 9.1 & 0.3 & 3.6 & 0.3 & 4.9 & 0.9 & 2.4 \\
\hline & Mean & 17.2 & 6.1 & 10.6 & 3.8 & 10.6 & 1.1 & 12.9 & 2.8 & 7.9 \\
\hline
\end{tabular}

Analysis of physical mechanical properties of soft soil

Based on the statistical results in Table 1 and Table 2, the engineering characteristics of soft soil in Georgetown are as follows:

(1) High natural moisture content, high void ratio and high compressibility; the natural moisture content of humus soil and muck is $84.5 \%$ to $202.0 \%$ and $50.3 \%$ to $86.7 \%$ respectively, and the void ratio is 2.523 to 4.039 and 1.228 to 2.153 respectively. we can see from the physical and mechanical mechanism of the soil that the high moisture content and high void ratio not only reflect the nature of the interaction between the mineral components and the medium of the soil, but also reflect the shear strength and compressibility, Generally, the higher the moisture content and the void ratio, the lower the shear strength and the higher the compressibility.

(2) Large plasticity index and liquidity index; The plasticity index of humus soil and muck is 28.6 to 54.0 and 17.9 to 34.1 respectively, and the liquidity index is 1.35 to 1.54 and 0.78 to 1.60 respectively. The greater the plasticity index, the finer the soil particles and the higher the fines content; the liquidity index reflects the soft and hard state of the soil, the larger the value, the softer the soil.

(3) Low intensity and high sensitivity; From the statistical results of direct shear and triaxial tests, it is known that the cohesion and internal friction angle of humus soil and muck are small, the cohesion and internal friction angle obtained by consolidation and quick shear test are relatively large, It shows that the drainage consolidation measures can effectively improve the shear strength of soil samples; Fig. 2 shows the triaxial shear strength of an undisturbed borehole and the shear strength distribution curves of undisturbed soil and remolded soil of adjacent vane-shear borehole, As can be seen from the figure, the triaxial shear strength is generally lower than the vane-shear strength of the undisturbed soil sample at the same depth, This is caused by disturbance of the soil in the process of triaxial sample preparation; It can be seen from the shear strength distribution curve of the vane-shear test 
that the shear strength of the remolded soil is significantly reduced. Therefore, the soft soil in this area has a high sensitivity.

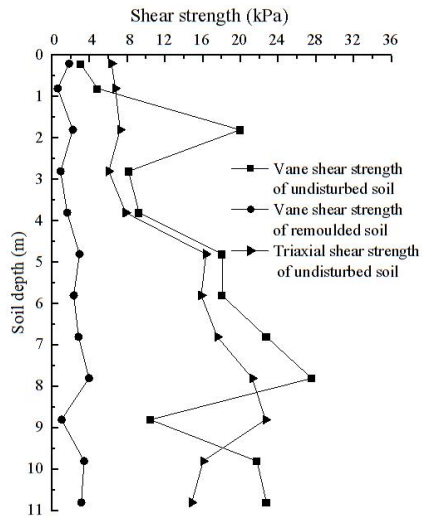

Fig.2 Triaxial shear strength of undisturbed soil and vane-shear strength distribution curve

(4) The increase of shear strength of humus soil after consolidation is not obvious, and the strength value is still very low. From the statistical results of consolidation fast shear and quick shear test, we can see that at the same consolidation time, The shear strength of humus soil and muck are improved, however, the shear strength of humus soil is still low after consolidation, and the average shear strength of muck is significantly higher than humus soil.

\section{Analysis and discussion of soft foundation treatment methods}

\section{Major Engineering Geological Problems}

(1) The annual rainfall in Georgetown is relatively large, the natural moisture content of humus soil layer and muck layer is high, and humus soil has strong water absorption, site drainage and lowering of the groundwater level are the primary issues facing the construction.

(2) Due to the large unexploited rainforests distributed in Georgetown, the organic matter content of the surface humus soil is extremely high and the engineering properties are extremely poor, and the shear strength of humus soil after consolidation is still very low, all the removal will result in a large workload and cost, and there is no clear demarcation between the humus soil layer and the muck layer. Therefore, the clearance of the humus soil and the determination of the cleaning depth are issues that need to be considered in the design and construction stage.

(3) It can be seen from the soil layer distribution and physical mechanical test results that the humus soil layer and muck layer are characterized by high natural moisture content, large void ratio, high compressibility and strong structure, Therefore, the local foundation is faced with many problems, such as uneven settlement and large amount of settlement and deformation.

(4) According to the statistical results of the soft soil mechanics index, the strength of the humus soil layer and muck layer in the area is low, and vertical shearing damage between soils can be easily induced, If the site is excavated and unloaded or replaced by a pile to form a manual slope, no treatment measures can easily cause landslides and endanger the stability of the foundation.

\section{Soft foundation Treatment Methods}

In view of the engineering characteristics and main engineering geological problems of the soft soil, the applicability of the soft foundation treatment methods used in China is discussed in combination with the local soil characteristics, and the following analysis is made on the soft foundation treatment methods of the sand pile composite drainage plate for the expansion project of the capital airport.

Introduction and Analysis of Domestic Soft foundation Treatment Method

At present, the soft ground treatment methods adopted by different types of construction projects in different regions in China are different. The drainage consolidation method, cement deep mixing method, compacted sand pile method and vibroflotation method are commonly used.

(1) Drainage consolidation method; This method is composed of a drainage system and a pressurizing system, By utilizing the characteristics of drainage consolidation of foundation soil, a preloading is applied, and various drainage conditions are added, so that the strength and stability of the foundation are improved simultaneously with consolidation settlement. Due to the large annual 
rainfall in Georgetown, Soft soil has high moisture content and strong compressibility, Therefore, drainage and preloading measures can effectively improve the stability and bearing capacity of the soft foundation in this region, and have strong applicability.

(2) Cement deep mixing method; Through special mixing and processing machines, cement and other reinforcing materials are mixed with foundation soil to form "cement soil" to reinforce the foundation, This method increases the strength of solids quickly and has small deformation; it does not require earth excavation and reduce the amount of earthwork; it has a small impact on the surrounding environment and is more suitable for local soft foundation reinforcement treatment.

(3) Compacted sand pile method; In this method, sand piles are driven into soft soil to form a composite foundation, for sandy foundations, the effect of compaction sand piles is to produce compaction and viscous compaction of the sand layers when the piles are formed; for clay foundations, the effect of compaction sand pile is displacement and drainage. Because this method uses large-scale vibration equipment, it is easy to cause deformation of the surrounding foundation, and the sensitivity of the local soil is high, the strength laws after disturbance is still uncertain. Therefore, whether this method is applicable to local soft soil foundation still needs further study.

(4) Vibroflotation method; The strong vibration of the vibrator is used to make the foundation soil particles compact, According to the difference in strengthening mechanism and effect, it can be divided into "vibration compaction method" suitable for sand base and "vibration replacement method" suitable for clay. This method is suitable for the local geological conditions, and has high speed of reinforcement, However, the strong vibration also has defects that cause deformation of the surrounding foundation and this method cannot discharge the water in the foundation. Therefore, this method is not suitable for local soft foundation treatment.

\section{Analysis of Soft foundation Treatment Methods in Georgetown}

(1) Soft foundation treatment method for expansion project of Capital Airport

At present, this project adopts the method of sand pile composite drainage plate to reinforce the soft foundation in the extension area, because the thickness of humus soil is undulating, and there is no clear boundary between the humus soil layer and the muck layer, so the humus soil is partially cleaned up along the depth range, Then the backfill medium fine sand is used to preload the soft foundation so as to eliminate the settlement of the soft soil during the service period as far as possible.

(2) Analysis and Discussion on the treatment effect of soft foundation

Fig. 3 shows the shear strength with depth variation curve of a borehole before and after soft foundation treatment. we can see from the figure that as the depth increases, the shear strength of soft soil shows a growing trend as a whole, indicating that the thicker the overburden, the higher the shear strength of the soil, therefore, in order to meet the strength of the soil layer, the overload preloading should be extended pressure time reasonably; The shear strength of soil is improved after sand pile composite drainage plate is used to treat the soft foundation, but the shear strength of the soil is still low in the depth range of $1.0 \mathrm{~m}$ to $5.0 \mathrm{~m}$, which is due to the soft soil is mainly humus soil. Therefore, the humus soil on the site surface should be removed as much as possible during soft foundation treatment.

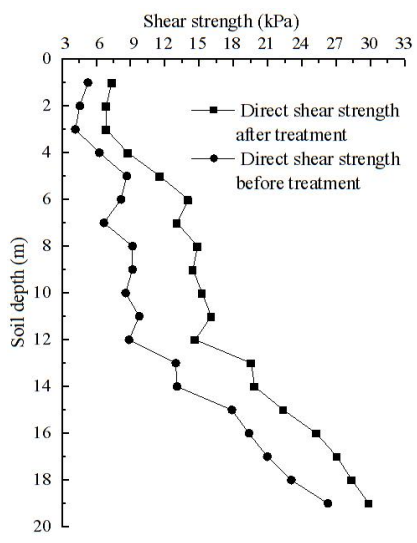

Fig.3 Fast shear strength distribution curve before and after foundation treatment 
Fig. 4 shows the shear strength distribution curves of two adjacent Vane-shear boreholes before and after soft foundation treatment. It can be seen from the figure that after the soft foundation treatment, the shear strength is obviously improved, which shows that the sand pile composite drainage plate is a suitable and effective soft foundation treatment method.

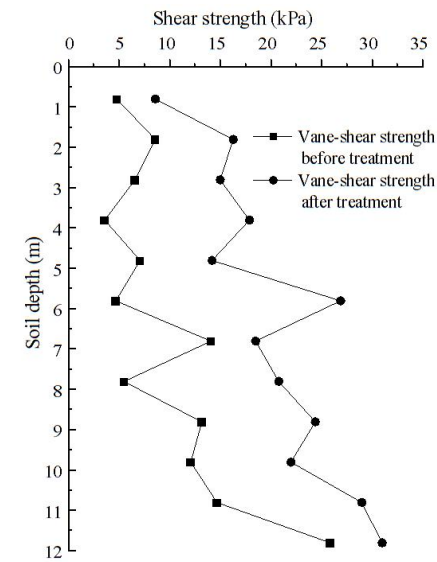

Fig. 4 Vane-shear strength distribution curve before and after foundation treatment

In addition, from the physical and mechanical properties of soft soil, the sensitivity of the local soft soil is high and the strength is suddenly reduced after the soil disturbance. Therefore, the loading rate should be controlled to reduce the disturbance to the soil layer when the sand pile composite drainage plate is carried out.

\section{Conclusions}

(1) In Georgetown area of Guyana, humus soil layer, muck layer, clay layer, and medium-fine sand layer are distributed along the depth, and the soft soil layer is humus soil layer and muck layer.

(2) Through the analysis of the physical and mechanical properties of the soft soil taken from the expansion project of the capital airport, it is concluded that the soft soil in this area has the characteristics of high natural moisture content, large void ratio, high compressibility, high plastic index and liquid index, low strength and high sensitivity, After the consolidation of humus soft soil, the growth of shear strength is not obvious, and the strength is still very low.

(3) Combined with the engineering characteristics of the soft soil in Georgetown, the main engineering geological problems in the stage of design and construction are summarized, and the drainage of the field, humus soil cleaning, cleaning depth determination, and uneven soil settlement are the main problems in the process of construction.

(4) The soft foundation treatment methods commonly used in China and its applicability in soft soil foundation treatment are introduced and analyzed. The method of treating the soft foundation of sand pile composite drainage plate in the expansion project of capital airport is analyzed. Finally, it is proved that this method is an effective and reasonable method which is suitable for local soft foundation treatment, and the suggestions of remove the surface humus, appropriately prolong the preloading time, reduce the disturbance to the soil layer and some other rationalization proposal are put forward.

\section{Acknowledgements}

This work was financially supported by the Tianjin Natural Science Foundation (16JCYBJC21700).

\section{References}

[1] LIN Yi-xi, AI Kang-hong, HUANG Liang-ji. "Issues of engineering characteristics and engineering construction of soft clay in ZhuHai region". Chinese Journal of Rock Mechanics and Engineering,25(2):3372-3376.

[2] Cui Hong-jun, Lu Xiao-lin, Wang Xiao-ming. "Reinforcement method of lacustrine soft foundation”. Chinese journal of Rock Mechanics and Engineering, 23(17): 2998-3002. 
[3] QU Ruo-feng, XU Guang-li , WANG Jin-feng. "Correlations of physical and mechanical properties of typical soft soils in Wuhan". Chinese Journal of Geotechnical Engineering, 36(2): $113-119$.

[4] LIU Yong-jian, LIU Xiang-qiu, LIU Ya-heng. "A Contrastive analysis of the physico-mechanical properties of soft soils in the pearl river delta". Journal of Guangdong University of Technology. 30(3): 30-36.

[5] LUO Jun-hui, MI De-cai, LIU Xian-lin. "Research and evaluation of engineering characteristics of soft soil". Journal of China \& Foreign Highway, 37(6): 42-45.

[6] GAO Zhi-yi(2015). Theory and practice of vacuum preloading. Beijing: China Communication Press Co., Ltd.,.

[7] MIU Lin-chang(2012). Mechanical properties and engineering practice of soft soil. Beijing: Science Press.

[8] YANG Wei-guang(1991), Ground base and foundation. Beijing: China Architecture\& Building Press.

[9] GAO Yan-bin, ZHANG Song-bo, GE Xiao-nan, “Comparisons of compression index of Chinese coastal soft clay and soils from foreign regions”. Rock and Soil Mechanics. 38(1): 2713-2720.

[10] ZHENG Xiao-jing, ZHANG Shi-shu, RAN Cong-yan, "Discussion on the engineering characteristics and the suitable treatment methods of dhaka soft clay in ban-gladesh". Journal of Engineering Geology. 23(1): 184-188.

[11] WANG Jun-qiao."Study on the engineering geological characteristics of soft soil deposited by volcanic ash in Bandung”. Railway Investigation and Surveying. 6(1): 50-52.

[12] HUANG Chen. "Study on the engineering properities of soft soil in BangLadesh of ganges river delta". Journal of Engineering Geology. 24(1): 1219-1223. 